\title{
Ética profesional en la búsqueda de bases de datos y motores de búsqueda: problemas, cuestiones, soluciones
}

\author{
Professional ethics in searching of databases and search engines: problems, issues, solutions
}

Tefko SARACEVIC

Saracevic, Tefko, Rutgers, the State University of New Jersey—School of Communication, Information and Library Studies, 4 Huntington Street NJ 088901 New Brunswick (Estados Unidos), tefko@scils.rutgers.edu.

\begin{abstract}
Resumen
Se proporciona una revisión de los problemas éticos relacionados con la búsqueda profesional de información tanto desde un punto de visto histórico como actual. Se formulan las cuestiones éticas básicas a las que se enfrentan los profesionales de la recuperación de la información. Se sugiere que el conjunto de recomendaciones éticas para búsquedas de información en línea que se elaboraron hace un cuarto de siglo pueden ser usadas, con las necesarias actualizaciones, también en el presente. A partir de ellas, se presenta y desarrolla un conjunto de recomendaciones éticas para los recuperadores de información y los procesos de búsqueda. Las conclusiones enfatizan la importancia de las consideraciones éticas en la búsqueda.
\end{abstract}

Palabras clave: Ética. Recuperación de información. Búsqueda de información.

\section{Introduction}

To start with a conclusion from a paper by Froelich (2004) that is still valid today: "Information ethics is a dynamic and evolving field, flowing from various disciplines and perspectives and cultures, critical in these times of intercultural exchange and dialog." While Froelich talked about a broader concern of information ethics in general, the conclusion is valid as well for ethics involved in searching, since it falls under the same broad umbrella of information ethics. And it is still critical, if not even more so.

Searching became ubiquitous. As searching tools and resources became universal, free and easy to use, it seems that just about everybody in the world who has Internet access also searches for information. Everybody is a searcher. In this environment the role of professional searchers has changed. It still encompasses searching on behalf of others, but it also needs to incorporate mastery of an ever growing number of diversified information resources, most Web based. However, searching is now also extended to incorpora-

\begin{abstract}
The purpose of this paper is to provide an overview of ethical concerns related to professional information searching from both a historical and contemporary point of view. Basic ethical questions and issues for searchers are formulated. A suggestion is made that a set of ethical guidelines for online searchers formulated a quarter century ago could be used, with some revision, even today. It is also suggested that "first do no harm" be the primary ethical principle for searchers. Following this a number of ethical guidelines for searchers and searching are formulated. Conclusions stress the importance of ethical consideration in searching.
\end{abstract}

Keywords: Etics. Information retrieval. Information search.

te a strong and wide educational component in teaching and guiding searching of their public and constituencies. Professional searchers search, but they also evaluate and assemble resources to enable effective searching by others, and in addition they teach, guide, instruct, train, lecture, and educate about searching. Searchers are not only searchers; they are also enablers, trainers, and educators. All these activities, of course, raise ethical issues and questions. While recognizing these additional activities -each with ethical concerns - only ethics as related to searching are discussed here.

The purpose of this paper is to provide an overview of ethical concerns related to professional information searching from both a historical and contemporary point of view. The orientation of the paper is toward professional searching; general aspects of searching by the public are not discussed. They create their own ethical concerns. 


\section{Some basics and questions}

Ethics (Greek from ethos, "character," "custom") refer to principles or standards of human conduct. Professional ethics regulate the behavior and conduct for a group as a profession. Hippocratic Oath is the oldest and most famous professional code of ethics; one of the guiding principles of that code was a professional's responsibility to "first, do no harm." So is searchers'.

Searching brings together people, technology, and information: people as users, people as professionals, information and communication technology and information resources. In these contacts and interactions many ethical issues and dilemmas arise. General professional activity of searchers is governed by the general code of ethics officially adopted by their professional societies. Codes of professional ethics in librarianship, information science, and computer science are general guides for ethical decision making (Kohler, n.d.). They have direct implications for searching. Moreover, specifics of searching and relations between users and searchers are governed by specific guidelines that are more or less unofficial, but nevertheless applicable.

Searching is rife with situations and demands where ethical choices have to be made and even ethical conduct explained. Thus, searchers need to be aware of ethics connected to searching and behave accordingly. This enhances not only their conduct, but reputation and integrity as well.

When searching for a user a professional searcher should start with: first, do no harm and then ask:

- What are the ethical principles are associated with my searching?

- What is expected of me as searcher in terms of ethical behavior?

\section{At issue}

The number and variety of information resources is huge and growing at a very high rate. This is referred as information explosion. As mentioned, great many people search for information. Few do it well. Even fewer can assess how well they are doing. Google is great. But there is much, much more to searching than Google. (There is even more to Google than that first page most people ever see and use). In other words there is more to searching than just searching.

One of the most important jobs for a librarian or information professional is to cope with information explosion. As professionals, librarians were always concerned with searching for information on behalf of users. But with the advent of electronic information resources and the Web, searching has changed in many ways. As mentioned, it has become a complex process involving interaction between several components related to people, information, and technology. A sign of a professional is an understanding of the complex processes and interactions involved in searching and putting them effectively to practice.

In general, as to searching information professional should be asking the following:

- How do I search effectively and efficiently a variety of electronic information resources for users?

- How do I evaluate what was searched and provided?

- How do I provide searching assistance and services to users and institutions?

\section{A bit of history}

Shaver, Hewison, \& Wykoff (1985). proposed a series of ethical guidelines for online searchers. Although, these guidelines were formulated a quarter century ago, with some terminological adjustment, they still have direct relevance for contemporary searching. After discussing various ethical issues facing online searchers, they formulated these guidelines (reproduced from the original article):

- The online searcher has an obligation to his or her institution and to the user to maintain awareness of the range of information resources available in order to fairly and impartially advise the client.

- The online searcher must Strilve to maintain a reasonable skill level in the systems available for searching

- The online searcher must eschew bias in the selection of appropriate databases and systems in order to meet the needs of the client.

- The online searcher must make the client aware of the searcher's level of expertise in searching a given database or system if that may affect the search results.

- The online searcher should be aware of the level of confidentiality required by both the setting and the request, and he or she should respect those boundaries

- The online searcher must make clear the appropiateness of the online search in meeting the client's needs and the limitations of the search process for the client's intentions. 
- The online searcher must guard against tendencie to fill the client's needs as the searcher sees them, but rather must utilize appropiate interview techniques to ascertain the client's needs

- The online searcher must, if appropiate, apprise the client of major errors in previous searches, both in strategy formulation and database selection.

- The online searcher must resist attempts by the client to select inappropiate databases and/or systems.

Shaver and colleagues started from the premise that online searchers face ethical problems which differ in kind and degree and from those provided by information service providers in traditional settings, including reference. This is true today as well. These guidelines can also serve to extract the basic areas of ethical concerns for contemporary searchers and searching. Suggestions for few guiding principles follow.

\section{Primary guiding principle: first do no harm}

\section{ACM code of ethics states:}

\begin{abstract}
"Harm" means injury or negative consequences, such as undesirable loss of information, loss of property, property damage, or unwanted environmental impacts. This principle prohibits use of computing technology in ways that result in harm to any of the following: users, the general public, employees, employers. [...] Well-intended actions, including those that accomplish assigned duties, may lead to harm unexpectedly. In such an event the responsible person or persons are obligated to undo or mitigate the negative consequences as much as possible. One way to avoid unintentional harm is to carefully consider potential impacts on all those affected by decisions made during design and implementation. [...] To minimize the possibility of indirectly harming others, computing professionals must minimize malfunctions by following generally accepted standards for system design and testing. Furthermore, it is often necessary to assess the social consequences of systems to project the likelihood of any serious harm to others. If system features are misrepresented to users, coworkers, or supervisors, the individual computing professional is responsible for any resulting injury.
\end{abstract}

If "searching" is substituted for "computing technology" and "design and implementation" and "library and information professionals" is substituted for "computing professionals," this statement summarizes the guiding ethical principles for professional conduct of searching.
Yes, by providing incomplete, inaccurate, and incorrect information a searcher could do harm, and possibly even significant harm, to a user.

\section{Further ethical guidelines for searchers}

No organizational professional code of ethics specific for searchers exists, but general principles of information ethics and of ethics codes from professional library and information associations apply. However, searching provides some unique relations between professionals and users warranting some additional specific guidelines. In this section some ethical guiding principles are extracted from numerous discussions about searching.

Professional searchers have close connection with users. They are gatekeepers involving possibly their confidence which raises urgency of adherence to ethical principles. Here is a short list of ethical concerns related to searches done on behalf of users:

- Searcher competente:

- evaluating level of service received.

- Searcher expertise and search results:

- apprising user and user consentí.

- Searcher bias:

- tendency toward certain resources.

- Search accuracy:

- or rather inaccuracy.

- Privacy and confidentiality:

- what goes on in searching stays in searching.

- Integrity:

- serving user as opposed to other interests.

Here are several major guidelines for searchers put in a personal context:

- A searcher's job is to provide information but not judge the uses to which it is put.

- Exception: short of serious imminent threat to another person or society.

- A searcher's job is to appraise sources \& provide information but not to give advice on subject matter.

- A searcher can provide health information but a searcher is not a doctor or psychiatrist to give medical or mental health advine. 
- A searcher can provide plumbing information but a searcher is not a plumber.

- A searcher is not an advice columnist.

- A searcher should know the authority, quality of information sources.

- Not to provide wrong information.

- Appraise user of possible quality problems.

- A searcher should be aware of user needs, context, limits

- to avoid providing information that may be inappropriate and wrongly interpreted, used.

- A searcher should provide information to user, advise on sources and give informational guidance, but a searcher should not do user's job.

\section{Conclusions}

The purpose of this paper was to provide an overview of ethical concerns related to professional information searching. In the process, a set of guiding ethical principles were reviewed and suggested.

The primary of these principles is to do no harm. The reason is straightforward: inaccurate, inadequate, and similar information has a potential to mislead the user and serve as a base for wrong, even harmful decisions and actions in all kinds of situations and fields. Plenty of historical examples can be offered. Doing no harm calls into questions a number of additional factors, including, among others, knowledge and competency of searchers. They have to be adequate to avoid harm. Thus proper professional and continuing education of searchers has a strong ethical component. It contributes to reducing possibility for harm.

Ethical concerns of and guidelines for searchers are not independent. They are or should be part and parcel of codes of ethics for library and information professionals in general. They should be part and parcel of all other professional ethical concerns as well. However, the practice of searching provides a unique connection between searchers and users. This reality should be taken into account to formulate ethical guidelines specific to searching, in addition to general ethical principles for professional conduct of library and information professionals. Searchers and searching also need specific ethical guidelines.

\section{References}

Association for Computing Machinery. (1992). Code of ethics and professional conduct. http://www.acm.org/ constitution/code.html (2010-05-18).

Froehlich, T. (2004). A brief history of information ethics. Textos universitaris de biblioteconomia i documentación. 13. http://www.ub.es/bid/13froel2.htm (2010-05-18).

Igesem, D. (2008) Search engines and the public use of reason. // Ethics and Information Technology, 10:4 (2008) 233-242.

Koehler, W. (n.d.). Ethics links to librarian and information manager associations WWW pages. .http://www. valdosta.edu/mlis/faculty/koehler/ethics/ (2010-05-18).

Shaver, D.B., Hewison, N.S., \& Wykoff, L.W. (1985). Ethics for online intermediaries. // Special Libraries, 76 (Fall) 238-245.

Recibido: 09-07-2010. Aceptado: 09-07-2010. 